\title{
(2) OPEN ACCESS \\ Branding of subjects affected with genetic syndromes of severe short stature in developing countries
}

\author{
Jaime Guevara-Aguirre, 1,2,3 Carolina Guevara, ${ }^{3}$ Alexandra Guevara, ${ }^{3}$ \\ Antonio AWD Gavilanes ${ }^{2}$
}

${ }^{1}$ College of Medicine, Universidad San Francisco de Quito, Quito, Pichincha, Ecuador 'Department of Pediatrics, Maastricht University, Maastricht, Limburg, The Netherlands

${ }^{3}$ Instituto de Endocrinologia y Metabolismo, IEMYR, Quito, Pichincha, Ecuador

\section{Correspondence to} Dr Jaime Guevara-Aguirre: jguevara@usfq.edu.ec

Accepted 27 January 2020

Check for updates

(c) BMJ Publishing Group Limited 2020. Re-use permitted under CC BY-NC. No commercial re-use. See rights and permissions. Published by BMJ.

To cite: Guevara-Aguirre J, Guevara C, Guevara A, et al. BMJ Case Rep

2020:13:e231737

doi:10.1136/bcr-2019-

231737

\section{SUMMARY}

In Ecuador, a developing South American country, subjects affected with genetic syndromes of severe short stature are commonly referred to as dwarfs or midgets. Furthermore, and because in earlier studies some patients had evidenced mental retardation, such abnormality is assumed to exist in all affected subjects. Herein, we present two discrete instances in which this type of branding occurs. The first is that of individuals with Laron syndrome who are still called 'dwarfs' and considered as having a degree of mental retardation despite evidence showing otherwise. A similar problem, that of a girl affected with a genetic syndrome of short stature, which might include mental retardation, is also discussed. Considering that stigmatising is a form of discrimination, it concerns us all. Hence, the use of derogatory terms such as midget, dwarf or cretin, that might unintentionally occur even when delivering the best and most devoted medical care, must be eliminated.

\section{BACKGROUND}

In the late 1980s, we discovered in Southern Ecuador the largest cohort of subjects affected with a form of growth hormone $(\mathrm{GH})$ resistance known as Laron syndrome (LS). ${ }^{1-3}$ This disease was initially described in Sephardic Jews and the Ecuadorian group appears genetically linked to such origin. ${ }^{4}$ LS is due to mutations in the growth hormone receptor (GHR) gene, ${ }^{5}$ which result in diminished serum concentrations of the insulin-like growth factor-I (IGF-I). This peptide is the physiological result of the normal interaction between $\mathrm{GH}$ and the GHR in the liver, ${ }^{6}$ and it is the main mediator of the growth promoting actions of GH in humans. Subjects affected with LS have some of the lowest serum concentrations of IGF-I of any other endocrine anomaly associated to short stature as well as miscellaneous abnormalities in most of their tissues and organs. ${ }^{78}$ The study of this group of patients has led to the understanding of new facets of the GHR biology and its function as well as of the consequences of the peripheral resistance to $\mathrm{GH}$ action. Clinical trials on the treatment of children affected with this condition led to the definition of safety and efficacy peculiarities of the therapy of GH insensitivity with the peptide known as recombinant human IGF-I (rhIGF-I). ${ }^{8-13}$ Similarly, studies of affected adults with LS allowed the understanding of discrete phenomena induced by low serum IGF-I concentrations and those related to the concomitantly enhanced insulin sensitivity occurring in these individuals. Indeed, the evaluation of their morbidity and mortality generated results that can be extrapolated to normal people thereby contributing to the clarification of present hypothesis about the genesis of cancer, diabetes and brain health in humans. ${ }^{14-16}$ The Ecuadorian subjects with LS have repeatedly stated in media interviews that they participated in such a wide range of studies because they wanted to help in the understanding of chronic diseases of ageing. Despite their contribution, many physicians, nurses, medical students, sociologists, journalists and society at large, still brand them with a term that they feel offended by and profoundly dislike: dwarfs.

We are hereby presenting two clinical cases, the first highlights issues derived from the use of a derogatory term which affected the entire life of one of these subjects and his family. The second underscores the many instances where branding might occur as well as issues related to the drug treatment of these conditions.

\section{CASE PRESENTATION}

\section{Case presentation (1)}

He is a smart, pleasant adult who after his recent marriage is truly happy in the company of his young wife and little girl. He enjoys all kinds of dishes, especially seafood, likes to tell stories and jokes and loves music. $\mathrm{He}$ is in his early 50 s and was diagnosed, more than three decades ago, as having LS due to a splice site mutation at codon 180 of exon 6 of the GHR gene (the $s s 180$ mutation). He was born of normal size but soon thereafter his height and weight initiated a relentless deterioration reflected by diminished SD scores (SDS) attained at the time of adulthood: height of 126 centimetres $(\mathrm{cm})$ (4 feet 1.6 inches) $(-6.8 \mathrm{SDS} /$ percentile $<1 \mathrm{pctl})$ and weight of $34.2 \mathrm{~kg}(-6.5 \mathrm{SDS} /<1 \mathrm{pctl})$. He has other abnormalities such as a small head circumference, frontal bossing, blue sclera, depressed nasal bridge, elbow limitation, acromicria (small hands and feet), excess body fat, diminished muscle mass and other clinical phenotypic anomalies. ${ }^{1}$ When he was a child he was treated as if he were younger and remembers to have always been branded with a term that he dislikes: dwarf. During his childhood, adolescence and early adulthood he was withdrawn, introverted and timid. He never received psychological support and barely completed primary and secondary school mainly because he did not want 
to attend and be called with pejorative names at educational centres and even in the street. Because of his shy attitude and his silence, he was considered to have diminished mental capacity. Nowadays, he has learned how to live with his condition and is happy with his family. He is satisfied since is helping physicians to understand the origins of cancer and diabetes; nevertheless, still feels offended and frustrated for being branded with derogatory terms.

This individual's narrative epitomises the same story, iterated every day, in the lives of each of the subjects experiencing this disease in Ecuador. He belongs to the cohort comprising onethird of the world's population with LS, and because of the large media attention that this group of patients has drawn in the last decade, he is aware of the importance that his disease has for understanding the roots of the so called 'chronic diseases of Western societies' as well as those of longevity. He and his peers generously cooperate in every trial done in the country with these purposes. Since his height generates physical limitations, it is very difficult for him to get or keep a job and, nowadays, is unemployed as many of these individuals are.

\section{Case presentation (2)}

This second case is presented to highlight the multiple and discrete instances and events when branding of patients with severe short stature may unintentionally occur. It can happen during the processes of diagnosis, treatment and, in general, when otherwise appropriate medical care of these individuals is being delivered. It is worth noticing that it can also occur during scientific and academic discussions and, surprisingly, is present in medical journals and books. As happens with children affected with LS, this case also illustrates the daily efforts done by these families to obtain an accurate diagnosis, delivered by expensive tests, as a requirement to get access to the growth peptides needed for the treatment of their diseased children. Most of the time, these attempts fail at the end due to the unaffordable cost of these medications in our countries, as it has been recently highlighted. ${ }^{17}$ Ironically, the careful study of these neglected patients, most of the time disclose new subcellular mechanisms that clarify the physiology of normal people; hence, benefits us all.

In 2018, a 5.7-year-old Ecuadorian girl was brought by her parents to our endocrinology clinic in Quito, Ecuador for evaluation of growth delay. During the mother's pregnancy, intrauterine growth restriction (IUGR) was diagnosed and, to promote fetal growth, the mother received a hypercaloric diet until delivery. In consequence, she developed obesity and distinctly remembers the appearance of large patches of acanthosis nigricans on her neck, armpits and inner thighs. It is certain that derangements of carbohydrate metabolism especially those in glucose and insulin concentrations must have accompanied the body composition and dermatological anomalies. Unfortunately, the laboratory result of these analytes was not documented in her clinical record.

During the second trimester of pregnancy, a disparity in gestational age estimations was seen. Indeed, sequential estimates of fetal age performed with ultrasound techniques were lower than those correctly made by the mother based on the day of conception. After an uneventful caesarean section surgery performed at 40.5 weeks of a pregnancy, according to the mother, and at 32.5 weeks according to the ultrasound examination, the newborn was small and a diagnosis of mild IUGR was established. Indeed, she had a small head circumference of $32 \mathrm{~cm}(-1.96 \mathrm{SDS} / 3$ pctl), along with slight reduction of body size (weight was 2830 $\mathrm{g}(-1.13 \mathrm{SDS} / 12 \mathrm{pctl})$; length $48 \mathrm{~cm}(-0.54 \mathrm{SDS} / 26 \mathrm{pctl})$. The mother gladly recalls that her baby girl was "small, attentive and beautiful, had bushy eyebrows, upright nose and generalized excess of hair, especially in the forehead". It should be noticed that during standard monitoring of their intrauterine life, and when children affected with IUGR are born, their disease is often referred to as a form of 'dwarfism' and, if their head size is lower than 2 SDS/2 pctl, it is considered as microcephaly.

During the first 3 months of life, the parents asserted that the baby's growth rate appeared to be normal but stated that she was 'very small' when compared with her peers. At 23 months of age, her weight was $8 \mathrm{~kg}$ (SDS $-3.6 /<1 \mathrm{pctl}$ ) and height was $73 \mathrm{~cm}(-3.4 \mathrm{SDS} /<1 \mathrm{pctl})$. Besides other normal biochemical parameters, $\mathrm{GH}$ concentrations during a standard test showed normal GH baseline values and normal GH responses at 60, 90 and $120 \mathrm{~min}$ after the administration of clonidine, a GH secretagogue. In addition, measurement of the serum levels of other molecules related to growth such as thyroid hormones,IGF-I and IGF-binding protein-3 concentrations were found within normal ranges. These studies were done to determine the cause of her 'dwarfism'.

Despite normal GH testing, rhGH might be effective to promote growth in children with pathological short stature; hence, her paediatrician decided to initiate a trial of $\mathrm{rhGH}$ therapy. After 6 months of treatment, substantial improvement was noted in her height that reached $81 \mathrm{~cm}(-2.31$ SDS / pctl 1.4) while weight remained low at $9 \mathrm{~kg}(-3.2 \mathrm{SDS} /<1 \mathrm{pctl})$. The additional weight SDS decrement can be attributed to the lipolytic effects of the recombinant peptide's administration. Because of the noticeable growth response, rhGH therapy was continued for two additional years. At 51 months of age weight was $11 \mathrm{~kg}(-3.1 \mathrm{SDS} /<1 \mathrm{pctl})$ and height showed a substantial improvement reaching $92 \mathrm{~cm}(-2.3 \mathrm{SDS} / 1 \mathrm{pctl})$. This means an increase in height SDS of 1.85 which is translated to a total gain of $19 \mathrm{~cm}$ and of $3 \mathrm{~kg}$ of weight during the 2.2 years of treatment. The corresponding annualised height velocity rate was an outstanding $8.6 \mathrm{~cm}$ per year.

The parents who describe their daughter as bright, affectionate, candid, happy, clever and independent but also as irritable, hyperactive and bold, were extremely satisfied that the cause of her child's 'dwarfism' appeared to be effectively treated. During rhGH treatment, this young girl became happier, playful and more assertive. When questioned on the subject, and without hesitation, the parents stated that after stopping the therapy her daughter's growth rate dramatically diminished and seriously affected her in various aspects including psychological.

At our first examination, we found a beautiful, alert, active, curious and healthy 5.7-year-old girl whose developmental skills and attitudes appeared normal for her age. Physical evaluation showed generalised hirsutism, low implantation of hair line, narrow forehead, well-defined and bushy eyebrows, long and curved eye lashes, upper lip hirsutism and small low-set ears. These features resemble those described in mild and moderate cases of the Cornelia de Lange syndrome (CdLS). ${ }^{18}$ Her weight was $13.1 \mathrm{~kg}(-3.4 \mathrm{SDS} /$ pctl 0$)$, height of $98.2 \mathrm{~cm}(-2.8 \mathrm{SDS} /$ pctl 0.2$)$ and head circumference of $48 \mathrm{~cm}(-2 \mathrm{SDS} /$ pctl 2$)$. The remaining physical examination was normal. The clinical diagnosis of this disease, which includes a form of harmonic short stature, was that of CdLS or of a CdL-like syndrome.

For later consideration, it should be noted that the impressive response to $\mathrm{rhGH}$ treatment necessarily implies that the GRH was effectively activated by the recombinant peptide and that such interaction resulted in further stimulation of the rat sarcoma/mitogen-activated protein kinase (RAS/MAPK) and 
phosphatidylinositol-3-kinase (PI3K)/Akt signalling cascades which mediate, via IGF-I, the majority of metabolic and proliferative actions of GH in body tissues. ${ }^{6715}$ The demonstration of the intactness of the GH/GHR/IGF-I axis in this child and of its high susceptibility to the influence of the rhGH is provided by the end results: clinically noticeable improvement in height, height velocity, height SDS and lipolysis. Concordantly, after the drug therapy was discontinued, the girl's growth rate slowed down. Without treatment, her growth and development will further deteriorate and she is destined to be very short. Everywhere she goes she will be identified as a 'midget' or as a 'dwarf', and if she becomes timid and shy, will be considered as having a certain degree of mental retardation.

Given that doubts existed about the aetiology of the various problems she had, a molecular genetic evaluation was performed. Sequential analyses of seven potential sites, seeking for changes and exonic deletion/duplication were executed and search for potential abnormalities was performed at the EP300, HDAC8, NIPBL, RAD21, SMC1A, SMC3 and ANKRD11 gene sites. An abnormal heterozygous anomaly, regarded as of uncertain significance, was identified as variant c.5786G $>$ A (p.ser1929Asn) of the ANKRD11 gene located at q24.2 of chromosome 16. Mutations in this site have been found in subjects affected by the KBG (KBG are the surname initials of the family first described with this illness) and in some CdLlike syndromes. ${ }^{19}{ }^{20}$ Our patient lacks features of the former and has several corresponding to the later. ${ }^{20}$ To be noted, when studying these types of patient, the term 'dwarfism', as a general denomination for shorter subjects, might arise at each instance of their clinical study.

While mutations in the NIPBL gene are responsible for as much as $50 \%$ of the cases of subjects with classical CdLS, and diverse abnormalities at the SMC1A, HDAC8, RAD21 and SMC3 genes have been reported in $20 \%$ of additional cases, ${ }^{21}$ in approximately $30 \%$ of affected subjects no definite mutation has been identified. ${ }^{22}$ An autosomal dominant pattern of inheritance is evident when NIPBL, RAD21 and SMC3 gene mutations are present and an X-linked dominant disease inheritance type is expected when HDAC 8 and SMC1A gene abnormalities are found. ${ }^{23}{ }^{24}$ The relevance of precisely identifying the responsible mutations and their inheritance pattern will help in proper genetic counselling and might avoid the appearance of new affected subjects who, besides their illness, will ineluctably be stigmatised, via branding, if society does not change in this matter. A pragmatic example of this issue can be appreciated in the case of the Ecuadorian cohort of subjects with LS. Since 1992, we have recommended to authorities the development of a genetic counselling programme based on a simple procedure: the detection of the heterozygous state of the ss 180 mutation. Until November 2019, such programme has not been implemented and new affected babies relentlessly appear every year.

Considering that specific subjects with the CdLS due to mutations in the ANKRD11 gene have exhibited mental deficiencies, ${ }^{25} 26$ a psychological evaluation was recommended for our patient. It was performed by a paediatric psychologist who found that this girl had cognitive functions above average. His report described her as 'stable and independent, impulsive, empathetic, sociable, cooperative and egocentric'. Sadly, her inherent positive features are slowly disappearing; she is starting to feel the effects of being short, is anxious now and eventually might become depressed. In summary, this intelligent young girl only needs rhGH treatment to reach a normal adult height and consequently avoid stigmatisation, disability and discrimination.

\section{CASE DISCUSSION}

The case of this Ecuadorian girl affected with CdL-like syndrome phenotype was and is a relatively easy clinical diagnosis; nevertheless, raises interesting scientific questions and suggests exciting scientific possibilities to explain them.

\section{Considerations about the birth size in this patient}

We propose that obesity-induced hyperinsulinaemia and insulin resistance necessarily occurred in the mother during pregnancy. It was clinically confirmed by the development of very important acanthosis nigricans. In general, insulin action includes the activation of the same intracellular pathways mediating the action of GH via IGF-I. ${ }^{27}$ Moreover, it should be noted that the RAS/ MAPK and PI3/AKT signalling cascades and subcellular mechanisms that mediate proliferation, differentiation, growth and survival of cells are similar for insulin and IGF-I and that associated molecules in these pathways are fundamentally the same. ${ }^{28}$ Since the blood of the fetus and the mother are shared, while the high concentrations of insulin in the mother exerted its metabolic effects on her own physiology, the development of acanthosis nigricans indicates a high degree of insulin resistance and a concomitant excess of circulating compounds such as glucose, amino acids, free fatty acids and others in the mother's blood. ${ }^{29}$ Hence, the growing fetus was definitely exposed via the placenta to a larger load of circulating nutrients present in the mother's circulation, event that should have led to fetal hyperinsulinaemia. ${ }^{30}$ Under such circumstance, rather than functioning as a metabolic hormone, fetal insulin might have acted as a growth factor in the fetus using various binding sites, including the insulin, IGF-I and hybrid insulin/IGF-I receptors. These events should have positively influenced fetal body size which could have been smaller without the dramatic changes initiated by maternal obesity. Concordantly, the deterioration of height and weight SDS after birth is probably due to the isolated effects of the ANKRD11 mutation devoid of the mitigating effects induced by the changes previously occurring in utero. In summary, there are inherent biological and therapeutic reasons to expect an excellent response to rhGH administration and heal the girl's severe short stature; however, her parents cannot afford the medication.

An analogous situation that illustrate the same fundamental basic principles about birth size is provided by observations in newborn children affected with LS. Their birth height and weight are quite normal; however, their growth and development rapidly deteriorate in the next few months after delivery. ${ }^{3}$ The normal intrauterine growth that these children exhibit despite the absence of its own GH actions must be due to the easy availability of nutrients and its fast delivery by the placenta, in association to a highly active insulin molecule in the fetal circulation. The enhanced insulin sensitivity and action will theoretically promote intrauterine growth and normal birth size but will also be responsible for a potent glucose lowering effect that should be attributed to the inherent absence of GH counterregulation found in this condition after birth. ${ }^{31}$ Indeed, the high rate of paediatric hypoglycaemia in these children, which can frequently lead to generalised seizures, ${ }^{3}$ reflects the high activity of the newborn's insulin molecule as well as the intactness of the PI3K/Akt and RAS/MAPK postreceptor elements shared by insulin and IGF-I.

\section{Treatment issues}

The rhGH treatment, which is a recommended approach for genetic cases of short stature, ${ }^{32} 33$ was feasible because there was 
a free-of-cost drug social programme for poor children affected with this and related conditions. When such plan was unexpectedly suspended treatment was discontinued in our patient as it was in every impoverished child in need of this expensive medication. To the present date, these children remain untreated, deeply affected and referred to as just additional cases of dwarfism'. Similarly, while the rhIGF-I treatment of children with LS, a standard therapeutic option as determined by the Food and Drug Administration and the European Medicines Agency can be obtained in many developed countries, in Ecuador and similar nations, it must be subsidised by the government. Until November of 2019, no patient has yet been treated in our country.

\section{Considerations about the ANKRD mutation}

As previously noted, mutations in the NIPBL, SMC1A, HDAC8, RAD21 and SMC3 genes account for approximately $70 \%$ of cases with CdLS. ${ }^{21-25}$ Furthermore, when broadening the spectrum of cohesinopathies such as KBG and $\mathrm{CdL}$ syndromes, mutations in the ANKRD11 gene were found in two patients with a CdLS overlapping phenotype. ${ }^{20}$ Individuals with the KBG syndrome have intellectual disability, learning difficulties, behavioural abnormalities and a small head, ${ }^{34}$ and it has been associated to heterozygous loss-of-function mutations in the ANKRD11 gene. ${ }^{20}$ Because mutations at this location are found in the KBG and CdL syndromes, two diseases that include mental deficiencies in classical cases, it could be assumed that such deficit could be derived from a direct genotype-phenotype correlation and be inherently linked to the genetic anomaly. Regardless, the fact that our patient possess an ANKRD11 heterozygous abnormality, a CdLS-like phenotype and severe growth deficit, illustrates that the clinical entity can exist along with a heterozygous defect in such gene and be associated to normal brain function.

In summary, we have presented the case of a 5.7-year-old girl with a CdLS-like phenotype associated to a heterozygous mutation in the ANKRD11 gene. Aside from the mild but distinct physical features of the syndrome, she has severe short stature temporarily mitigated by an outstanding rhGH therapy response. If she could afford treatment she could avoid a disability status and, in the process, be free of branding and discrimination.

\section{GLOBAL HEALTH PROBLEM LIST Main issues}

First main issue (MI): Branding thereby discrimination of patients with severe short stature using pejorative terms still happens worldwide and today.

Second MI: The long-standing belief that patients with severe short stature usually have diminished intelligence occurs frequently.

\section{Secondary issues}

First secondary issue (SI): Precise genetic diagnoses which influence early treatment and outcome in clinical syndromes are not routinely performed in developing countries.

Second SI: When indicated, rhGh or rhIGF-I treatment in several syndromes of severe short stature probably eliminates most sources of disability but is not routinely done in developing countries.

\section{GLOBAL HEALTH PROBLEM ANALYSIS}

\section{Main issues}

First MI: Branding of subjects who display physical or mental abnormalities comes from ancient time $\mathrm{e}^{35}$ and will continue until discrimination disappears and people become more tolerant and compassionate.

In a closely related matter, pertinent to the cases we are presenting and further underscoring our main argument, it should be noted that the English word 'dwarf' comes from the Old English 'dwergh', which might be derived from the Proto-Germanic 'dwergoz', in turn taken from the Proto-IndoEuropean term 'dhwerg-hos'. This last denomination has been linked to the root meaning 'to deceive', ${ }^{36}$ implying an inherent defective moral feature that has been inexplicably associated to a physical disability, hence adding biased sources to further promote discrimination.

In any case, it would be rewarding to see that medical personnel, specifically trained to alleviate pain and mitigate disease, start teaching society to abolish the use of derogatory terms when speaking about patients. Maybe the clearest example of this delicate issue is provided by the commonly employed and highly offensive term 'cretin', which is still used today in the medical field. It refers to subjects who have severe short stature and deep neurological deficit due to severe congenital hypothyroidism. ${ }^{37}$ This expression comes from the French word 'crétin' which is derived from the Alpine expression 'crestin' that means 'a dwarfed and deformed idiot'. It must be considered that these patients are humans whose entire biology has been irreversibly devastated by the lack of thyroid hormones and do not deserve to be further affected. This disorder will eventually be eliminated; however, the term will prevail if we do not address the discrimination that its origin involves.

Regarding the two cases presented, it should be noted that there are more than 300 causes of severe short stature which are of genetic, epigenetic or environmental aetiology. Achondroplasia is the most common cause of severe short stature (70\%) and occurs in 4-15 of 100000 live births. ${ }^{38}$ The second most frequent case is that of GH deficiency, which has been identified in 1 out of 3800 live births, annually affects between 1 and 2 individuals per 100000 people, and its general characteristics have recently been reviewed. ${ }^{39}$ Other miscellaneous causes are distributed among several distinct medical illnesses. The number of people affected with these conditions is of no major importance from an epidemiological or from a classic global health perspective and, in fact, these subjects are a minority. Nevertheless, and contextually considered, our argument is that the initial approach to any suffering individual defines the usual conduct that care providers take while delivering their health services. It thereby affects the whole patient population and compromises the entire medical profession. Hence, when a single patient is stigmatised, such action disturbs the very basis and the quintessential essence of medicine: compassion and respect for all humans.

Apart from the dramatic example of individuals with severe congenital hypothyroidism accompanied by irreversible neurological disease; besides the cases of achondroplasia, GH deficiency and the case of the patient affected with the CdLS above described, there are many other instances where branding of short stature individuals occurs, for example, Carpenter's and LS. The latter was initially called Laron Type Dwarfism in earlier publications. ${ }^{7}$ It was only after a patient told us that they were offended by the term 'dwarf' used by us and others, that we realised that an incongruity happened when we, the same physicians who intended to heal them, were aggravating our patient's condition by means of verbal accentuation and branding of one of the cardinal features of the syndrome we were aiming to understand and treat. Since then, we never used that term again and encourage all physicians to do the same. The 
widespread insensibility concerning the use of the term 'dwarf' or similar ${ }^{40-49}$ underscores the present need of finally eliminating such terms from the medical lexicon. To this regard, it is relevant to quote at this time Dr David W Smith, the father of modern dysmorphology. In a 1977 statement, this iconic paediatrician firmly suggested that physicians '.... abandon such categorical terms such as 'midget' or 'dwarf' that tend to brand a person based on size and proportion alone'. ${ }^{50}$ His wise words strongly resonated yesterday and should do it today as well. Besides causing individual and family pain and discomfort, branding in our country also causes that affected subjects abandon a proper education and a chance of a better future. The minimal attention that authorities have given to the provision of growth promoting medications for these subjects is underscored by the fact that despite receiving worldwide attention in the last three decades, these children remain untreated until the present day (November of 2019).

Second MI: The tendency to assume that subjects affected with genetic syndromes probably have diminished intelligence also happens in various diseases such has Carpenters syndrome, ${ }^{51}$ also known as acro-cephalo-poly-syndactyly (ACPS). This is an illness that may present with multiple somatic abnormalities that include short stature. As many as 30 different anomalies, including mental retardation, have been carefully described in this syndrome. ${ }^{51}$ Most instances of ACPS are due to a dysfunction of the RAS-related enzyme Rab23, a GTPase belonging to the Rab superfamily that is involved in signal transduction and protein trafficking within the cell, and it is due to mutations in the Rab23 gene $(6 \mathrm{p} \mathrm{12.1)})^{52}$ The second most common mutation occurs in the multiple epidermal growth factor-like domain 8 (MEGF8) gene (19q 13.2). ${ }^{53}$ The ubiquitous nature of the coded proteins explains the wide range of dysmorphia present in the clinical phenotype of these subjects, and both intellectual disability and normal intelligence have been described. Surprisingly, from the very wide and ample range of potential abnormalities in subjects affected with ACPS,${ }^{54}$ normal intelligence is selected and reported as a rarity instead of simply being treated as just another finding. This is another example of how pervasive the possibility of mental retardation is, as a source of branding, for an entire kind of patients.

The case of LS also highlights the general belief that syndromes of short stature necessarily include diminished intelligence. Subjects with this condition display many phenotypic features besides severe short stature. They might have diminished head circumference, frontal bossing, blue sclera, crowded teeth, reduced inferior segment, acromicria, limitation of elbow extension, delayed onset of puberty and other minor anomalies. In a similar manner to that of the ACPS syndrome, in the case of LS, one feature, the reduced head circumference thereby small head, was taken as an indicative of diminished mental ability without formal psychometric comparative testing. As a derivative, the mistaken assumption that mental retardation was an inherent characteristic of the low IGF-I serum concentrations remained as a possibility for many years in academic circles.

The Ecuadorian cohort with LS is also the only genetically homogeneous cohort in the world and has been carefully studied for the last three decades in comparative studies using their relatives as controls and, invariably, normal intelligence in most subjects with growth hormone receptor deficiency (GHRD) has been found. ${ }^{1-3} 16$ Despite corresponding academic articles on this specific matter, most local medical students and practitioners still believe that diminished intelligence is common in the Ecuadorian patients, despite published data demonstrating otherwise. This attitude might be due to the large influence of earlier
Patient's perspective

Translation to English:

26 September 2019

To whom it may concern:

I was born in southern Ecuador. I am (age on the $30 \mathrm{~s}$ ) years old, and recently had my birthday, when I was 6 was diagnosed as having "Laron syndrome".

Since I can acknowledge, many people, including physicians, nurses and other health professionals, besides the people surrounding me, refer to me as 'dwarf'. For it I have asked and begged for many years my physician to do anything humanly possible, so such offensive word is eliminated, when referring to us, especially the members of the medical body.

\section{Learning points}

- Branding of mental or physical characteristics of subjects affected with syndromes of severe short stature must be avoided in developing countries and worldwide.

- Efforts to eliminate derogatory terms when referring to diseased individuals should ideally take place at home, in schools, colleges and especially in medical colleges and universities.

- Children affected with genetic syndromes in developing countries need aid to access to early molecular diagnoses since it leads to earlier treatment and outcome.

- These children also need specific social programme, supported by their corresponding governments, to obtain the expensive therapies they urgently required to avoid or mitigate disability, especially for those whom for reasons of poverty cannot afford it.

publications suggesting that mental retardation is a distinctive feature of LS. ${ }^{71}{ }^{42}$

Since Ecuadorian patients with LS due to GHRD had no such anomaly and instead displayed an outstanding school performance in many instances, ${ }^{1-3}$ we designed a highly controlled study using the best tools available in the early 90 's to further explore this conflicting issue. It was found that Ecuadorian subjects with LS due to GHRD, at the very least, do have normal and many times better parameters of mental functioning when compared with their relatives. The corresponding study was done using intelligence tests validated in cross-cultural research and were designed to minimise the effects of physical size, motor coordination and cultural background. Results demonstrating at least normal intelligence in Ecuadorian subjects affected with GHRD, ${ }^{55}$ contradicted in an objective and systematic fashion, previous assumptions that linked LS to mental retardation.

Regardless, these fascinating individuals have attracted the wide attention of scientists in the last three decades and of the media in the last 8 years. Notably, affected subjects have gladly and still cooperate in studies as well as in media interviews. Our contention is that Society owes them for their contribution in the understanding of chronic diseases of modern Western conglomerates and that also owes them, at least, the elimination of their branding as a form of warm retribution.

Altogether, it is difficult to understand why subjects affected with syndromes that have severe short stature among their features are assumed to have mental retardation. The fascination 
that society has with taller individuals and its preference for them might have common roots with this observation.

\section{Secondary issues}

First SI: Early diagnosis always determines early treatment in genetic syndromes. It also leads to timely genetic counselling for the affected families and should eventually result in adequate design of proper public policies directed to help these individuals. In developing countries, sophisticated genetic studies aimed to attain these objectives are not easily available and families are forced to rely on costly testing done abroad. Regarding therapeutic options, they have no choice but to rely on fragile and unstable social programme providing the drugs indispensable to treat their diseased children. Indeed, the logistics and costinherent hindrances that these procedures and treatments entail impede the appropriate care of affected subjects and usually lead to permanent disability.

Second SI: In diseases that include severe short stature such as GH deficiency, LS, CdLS and Turner syndrome as well as in related conditions, rhGh or rhIGF-I treatment aimed to improve adult height is indicated. ${ }^{56-59}$ According to published results, such therapy provides good results and probably eliminates the main sources of their disability ${ }^{60}$; however, treatment is not done in most instances for financial reasons and lack of social programme.

Contributors JG-A ss the patient's doctor, wrote the manuscript, supervised all authors. CG did the medical history and physical examination with JG-A collected most references, wrote some paragraphs, reviewed the manuscript. AG helped in writing all drafts of the manuscript, reviewed and edited all versions of the manuscript. AAWDG wrote some paragraphs, provided various references and reviewed the manuscript.

Funding The authors have not declared a specific grant for this research from any funding agency in the public, commercial or not-for-profit sectors.

Competing interests None declared.

Patient consent for publication Parental/guardian consent obtained.

Provenance and peer review Not commissioned; externally peer reviewed.

Open access This is an open access article distributed in accordance with the Creative Commons Attribution Non Commercial (CC BY-NC 4.0) license, which permits others to distribute, remix, adapt, build upon this work non-commercially, and license their derivative works on different terms, provided the original work is properly cited and the use is non-commercial. See: http://creativecommons.org/ licenses/by-nc/4.0/.

\section{REFERENCES}

1 Guevara-Aguirre J, Rosembloom AL, Fielder PJ, et al. Growth hormone receptor deficiency in Ecuador: clinical and biochemical phenotype in two populations. J Clin Endocrinol Metab 1993;76:417-23.

2 Rosenbloom AL, Aguirre JG, Rosenfeld RG, et al. The little women of Loja - growth Hormone-Receptor deficiency in an inbred population of southern Ecuador. $N$ Engl J Med 1990:323:1367-74

3 Rosenfeld RONG, Rosenbloom AL, Guevara-Aguirre J, et al. Growth hormone (GH) insensitivity due to primary GH receptor deficiency. Endocr Rev 1994:15:369-90.

4 Velez C, Palamara PF, Guevara-Aguirre J, et al. The impact of Converso Jews on the genomes of modern Latin Americans. Hum Genet 2012;131:251-63.

5 Berg M, Argente J, Chernausek S, et al. Diverse growth hormone receptor gene mutations in Laron syndrome. Am. J. Hum. Genet;993:998-1005.

6 Maiter D, Walker JL, Adam E, et al. Differential regulation by growth hormone (GH) of insulin-like growth factor I and GH receptor/binding protein gene expression in rat liver. Endocrinology 1992;130:3257-64.

7 Laron Z. Laron-Type Dwarfism (Hereditary Somatomedin Deficiency): A Review. In: Frick P, von Harnack GA, Kochsiek K, et al, eds. Advances in internal medicine and pediatrics. 51. Berlin, Heidelberg: Springer, 1984.

8 Guevara-Aguirre J, Rosenbloom AL, Vaccarello MA, et al. Growth hormone receptor deficiency (Laron syndrome): clinical and genetic characteristics. Acta Paediatr 1991;80:96-103.

9 Klinger B, Laron Z. Three year IGF-I treatment of children with Laron syndrome. J Ped Endocrinol Metab 1995;8:149-58.
10 Guevara-Aguirre J, Vasconez O, Martinez V, et al. Rosenfeld Rg: a randomized, double blind, placebo controlled trial on safety and efficacy of recombinant human insulin-like growth factor-I in children with growth hormone receptor deficiency. J Clin Endocrinol Metab 1995:80:1393-8.

11 Guevara-Aguirre J, Rosenbloom AL, Vasconez O, et al. Two-Year treatment of growth hormone $(\mathrm{GH})$ receptor deficiency with recombinant insulin-like growth factor I in 22 children: comparison of two dosage levels and to GH-treated GH deficiency. J Clin Endocrinol Metab 1997;82:629-33.

12 Chernausek S, Backeljauw P, Frane J, et al. Gh insensitivity syndrome Collaborative Group. long-term treatment with recombinant IGF-I in children with severe IGF-I deficiency due to growth hormone insensitivity. J Clin Endocrinol Metab 2007;92:902-10.

13 Guevara-Aguirre J, Rosenbloom AL, Guevara-Aguirre M, et al. Recommended IGF-I dosage causes greater fat accumulation and osseous maturation than lower dosage and may compromise long-term growth effects. J Clin Endocrinol Metab 2013;98:839-45.

14 Leslie M. Growth defect blocks cancer and diabetes. Science 2011:331:837.

15 Guevara-Aguirre J, Balasubramanian P, Guevara-Aguirre M, et al. Growth hormone receptor deficiency is associated with a major reduction in pro-aging signalling, cancer, and diabetes in humans. Sci Trans/Med 2011;3.

16 Nashiro K, Guevara-Aguirre J, Braskie MN, et al. Brain structure and function associated with younger adults in growth hormone receptor-deficient humans. J. Neurosci. 2017;37:1696-707.

17 Rowlands A, Acosta-Gualandri A, Guevara-Aguirre J, et al. Who and national Lists of essential medicines in Mexico, central and South America, and the Caribbean: are they adequate to promote paediatric endocrinology and diabetes care? BMJ Glob Health 2016;1:e000114

18 Rohatgi S, Clark D, Kline AD, et al. Facial diagnosis of mild and variant CdLS: insights from a dysmorphologist survey. Am J Med Genet A 2010;152A:1641-53.

19 Low K, Ashraf T, Canham N, et al. Clinical and genetic aspects of KBG syndrome. Am J Med Genet A 2016;170:2835-46.

20 Parenti I, Gervasini C, Pozojevic J, et al. Broadening of cohesinopathies: exome sequencing identifies mutations in ANKRD11 in two patients with Cornelia de Langeoverlapping phenotype. Clin Genet 2016;89:74-81.

21 Mannini L, Cucco F, Quarantotti V, et al. Mutation spectrum and genotypephenotype correlation in Cornelia de Lange syndrome. Hum Mutat 2013;34:1589-96.

22 Huisman SA, Redeker EJW, Maas SM, et al. High rate of mosaicism in individuals with Cornelia de Lange syndrome. J Med Genet 2013;50:339-44.

23 Russell KL, Ming JE, Patel K, et al. Dominant paternal transmission of Cornelia de Lange syndrome: a new case and review of 25 previously reported familial recurrences. Am J Med Genet 2001;104:267-76.

24 Schoumans J, Wincent J, Barbaro M, et al. Comprehensive mutational analysis of a cohort of Swedish Cornelia de Lange syndrome patients. Eur J Hum Genet 2007;15:143-9.

25 Ansari M, Poke G, Ferry Q, et al. Genetic heterogeneity in Cornelia de Lange syndrome (CdLS) and CdLS-like phenotypes with observed and predicted levels of mosaicism. J Med Genet 2014;51:659-68.

26 Yuan B, Pehlivan D, Karaca E, et al. Global transcriptional disturbances underlie Cornelia de Lange syndrome and related phenotypes. J Clin Invest 2015;125:636-51.

27 Salter J, Best CH. Insulin as a growth hormone. BMJ 1953;2:353-6.

28 Siddle K. Signalling by insulin and IGF receptors: supporting acts and new players. J Mol Endocrinol 2011;47:R1-10.

29 Sivan E, Boden G, Acids FF. Insulin resistance, and pregnancy. Curr Diab Rep 2003:3:319-22.

30 Seck A, Hichami A, Doucouré $S$, et al. Th1/Th2 dichotomy in obese women with gestational diabetes and their Macrosomic babies. J Diabetes Res 2018;8474617.

31 Guevara-Aguirre J, Rosenbloom AL, Balasubramanian P, et al. Gh receptor deficiency in Ecuadorian adults is associated with obesity and enhanced insulin sensitivity. J Clin Endocrinol Metab 2015;100:2589-96.

32 Cohen P, Rogol A, Deal C, et al. Consensus statement on the diagnosis and treatment of children with idiopathic short stature: a summary of the growth hormone research Society. the Lawson Wilkins Pediatric 2008;93:4210-7.

33 Sandberg D Colsman M. growth hormone treatment of short stature: status of the quality of life rationale. Horm Research 2005:275-83.

34 Morel D, Foster J, Tekin M. KBG syndrome. Orphanet J Rare Dis 2017;12.

35 Dasen V. Dwarfs in ancient Egypt and Greece. Oxford university press, Oxford (UK) 2013:54-8. ISSBN 0-199-68086-8.

36 Anderson J. Dwarf. Lexiculture: papers on English words and culture, vol. 2, article 2, 2016. Available: http://glossographia.files.wordpress.com/2014/03dwarf.pdf

37 Salisbury S. Cretinism: the past, present and future of diagnosis and cure. Paediatr Child Health 2003:8:105-6.

38 Pauli RM. Achondroplasia: a comprehensive clinical review. Orphanet J Rare Dis 2019;14:1-49.

39 Dattani MT, Malhotra N. A review of growth hormone deficiency. Paediatr Child Health 2019;29:285-92.

40 Weinberg MS. The problems of Midgets and dwarfs and organizational remedies: a study of the little people of America. J Health Soc Behav 1968;9:71. 
41 Laron ZVI, Galatzer A. Effect of hgH on head circumference and IQ in isolated growth hormone deficiency. Early Hum Dev 1981;5:211-4.

42 Shevah O, Kornreich L, Galatzer A, et al. The intellectual capacity of patients with Laron syndrome (LS) differs with various molecular defects of the growth hormone receptor gene. Correlation with CNS abnormalities. Horm Metab Res 2005:2-5.

43 Alves RM, Uva P, Veiga MF, et al. Novel ANKRD11 gene mutation in an individual with a mild phenotype of KBG syndrome associated to a GEFS + phenotypic spectrum: a case report. BMC Med Genet 2019;20:1-7.

44 Sirmaci A, Spiliopoulos M, Brancati F, et al. Mutations in ANKRD11 cause KBG syndrome, characterized by intellectual disability, skeletal malformations, and macrodontia. Am J Hum Genet 2011;89:289-94

45 Voss LD, Sandberg DE. The psychological burden of short stature: evidence against. Social Science Medicine 2004:S29-33.

46 Ablon J. Dwarfism and social identity: self-help group participation. Soc Sci Med B 1981:15:25-30

47 Siegel PT, Clopper R, Stabler B. Psychological impact of significantly short stature. Acta Paediatr 1991:80:14-18

48 Ablon J. The nature of stigma and medical conditions. Epilepsy \& Behavior 2002;3:2-9

49 Heider JD, Scherer CR, Edlund JE. Cultural stereotypes and personal beliefs about individuals with dwarfism. J Soc Psychol 2013;153:80-97.

50 Smith D. Growth and its disorders". Volume VI in the Series Major problems in Clinical Pediatrics; 197.

51 Robinson LK, James HE, Mubarak SJ, et al. Carpenter syndrome: natural history and clinical spectrum. Am J Med Genet 1985:20:461-9.
52 Jenkins $\mathrm{D}$, Seelow $\mathrm{D}$, Jehee FS, et al. Rab23 mutations in carpenter syndrome imply an unexpected role for hedgehog signaling in cranial-suture development and obesity. Am J Hum Genet 2007:80:1162-70.

53 Twigg SRF, Lloyd D, Jenkins D, et al. Mutations in multidomain protein MEGF8 identify a carpenter syndrome subtype associated with defective lateralization. Am J Hum Genet 2012;91:897-905.

54 Tarhan E, Oğuz H, Safak MA, et al. The carpenter syndrome phenotype. Int J Pediatr Otorhinolaryngol 2004:68:353-7.

55 Kranzler J, Rosenbloom A, Martinez V, et al. Normal intelligence with severe insulin-like growth factor I deficiency due to growth hormone receptor deficiency: a controlled study in genetically homogeneous population. J Clin Endocrinol Metab 1998;83:1953-8.

56 Pfäffle R. Hormone replacement therapy in children: the use of growth hormone and IGF-I. Best Pract Res Clin Endocrinol Metab 2015;29:339-52.

57 Bolar K, Hoffman AR, Maneatis T, et al. Long-Term safety of recombinant human growth hormone in Turner syndrome. J Clin Endocrinol Metab 2008;93:344-51.

58 Allen D. Growth hormone therapy for short stature: is the benefit worth the burden? Pediatrics 2015;118:2006-329.

59 Sandberg DE, Colsman M. Growth hormone treatment of short stature: status of the quality of life rationale. Horm Res Paediatr 2005;63:275-83.

60 Rosenfeld RG, Attie KM, Frane J, et al. Growth hormone therapy of Turner's syndrome: beneficial effect on adult height. J Pediatr 1998:132:319-24.

Copyright 2020 BMJ Publishing Group. All rights reserved. For permission to reuse any of this content visit

https://www.bmj.com/company/products-services/rights-and-licensing/permissions/

BMJ Case Report Fellows may re-use this article for personal use and teaching without any further permission.

Become a Fellow of BMJ Case Reports today and you can:

- Submit as many cases as you like

- Enjoy fast sympathetic peer review and rapid publication of accepted articles

- Access all the published articles

Re-use any of the published material for personal use and teaching without further permission

Customer Service

If you have any further queries about your subscription, please contact our customer services team on +44 (0) 2071111105 or via email at support@bmj.com.

Visit casereports.bmj.com for more articles like this and to become a Fellow 